\title{
DESIGN FEATURES OF THE TOKAMAK TEXTOR
}

\author{
O. NEUBAUER, * G. CZYMEK, B. GIESEN, P. W. HÜTTEMANN, M. SAUER, \\ W. SCHALT, and J. SCHRUFF Institut für Plasmaphysik, Forschungszentrum Jülich GmbH \\ EURATOM Association, Trilateral Euregio Cluster, D-52425 Jülich, Germany
}

Received April 23, 2004

Accepted for Publication August 31, 2004

TEXTOR is the Tokamak Experiment for Technology Oriented Research in the field of plasma-wall interaction. The scope includes a detailed analysis of particle and energy exchange between the plasma and the surrounding chamber as well as active measures to optimize the first wall and the plasma boundary region. TEXTOR is a medium-sized tokamak belonging to the class of moderate-field but large-volume devices having a circular cross section of the plasma and an iron core. The plasma major radius is $1.75 \mathrm{~m}$, and the minor radius is $0.47 \mathrm{~m}$. The maximum plasma current is $0.8 \mathrm{MA}$, the maximum field is $3 T$, and the maximum pulse length is $10 \mathrm{~s}$. TEXTOR is fed directly from the 110-kV grid using an installed converter power of $\sim 300$ MVA. The inner wall of TEXTOR is equipped with several specially shaped limiters being partly remotely movable. Special design features of TEXTOR are excellent access for diagnostics to domains near the wall, large portholes suitable for implementing methods to control the plasma boundary, facilities to heat the vacuum vessel and the liner, and provisions for exchange of the liner. TEXTOR has been upgraded with auxiliary heating systems (neutral beam injection, radio-frequency heating, and microwave heating of $9 \mathrm{MW}$ in total), a toroidal pumped limiter, an upgraded magnetization coil, and recently the dynamic ergodic divertor (DED). The DED is a novel flexible tool to influence transport parameters at the plasma edge and to study the resulting effects on heat exhaust, edge cooling, impurity screening, plasma confinement, and stability. The number of special features and the flexibility of TEXTOR provide excellent opportunities for important contributions to fusion research.

KEYWORDS: tokamak design, neutral beam injection, dynamic ergodic divertor

\section{INTRODUCTION}

TEXTOR (Fig. 1) is the Tokamak Experiment for Technology Oriented Research in the field of plasmawall interaction. ${ }^{1}$ The scope not only includes a detailed analysis of particle and energy exchange between the plasma and the surrounding chamber but also involves active measures to optimize the first wall and the plasma boundary region in such a way that wall erosion, particle release, and impurity influx to the plasma core are reduced to tolerable levels. In order to comply with these objectives, TEXTOR has a number of special design features such as

- excellent access for diagnostics to domains near the wall

- large portholes suitable for implementing methods to control the plasma boundary

\footnotetext{
*E-mail: o.neubauer@fz-juelich.de
}

- facilities to heat the vacuum vessel and the liner

- provisions for exchange of the liner. with

During several upgrades TEXTOR has been equipped

- auxiliary heating systems [neutral beam injection (NBI) radio-frequency (rf) heating, and microwave heating]

- a toroidal pumped limiter

- an upgraded magnetization coil

- and recently the dynamic ergodic divertor (DED).

This paper describes the features of the tokamak TEXTOR from a technical point of view. Emphasis is given to the mechanical and electrical systems of the machine itself followed by a description of the controls and data acquisition. Finally, the important extensions of TEXTOR such as neutral beam heating and the unique DED are focused on. 


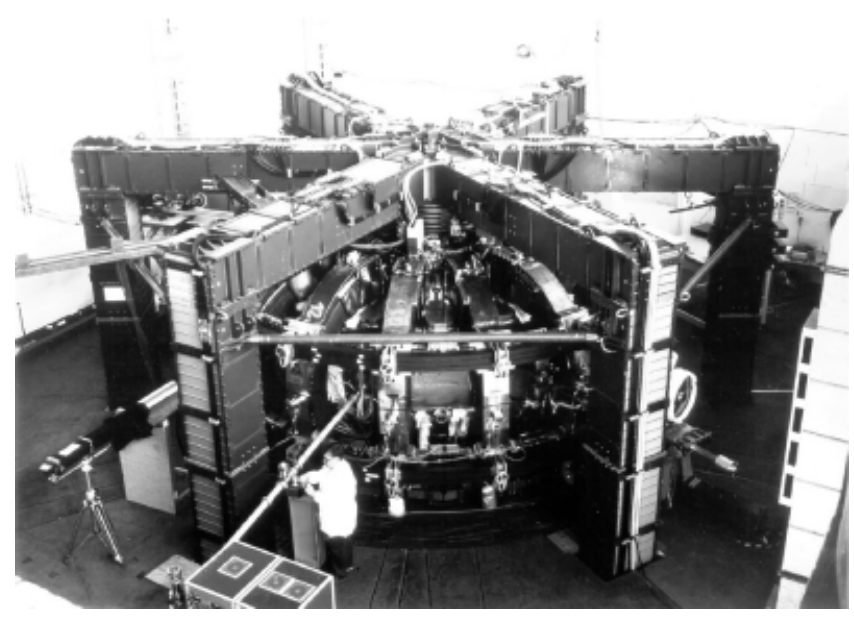

Fig. 1. Photograph of the TEXTOR tokamak showing the device before installation of diagnostics and auxiliary heating systems.

\section{TEXTOR DEVICE}

TEXTOR is a medium-sized tokamak belonging to the class of moderate-field but large-volume devices having a circular cross section of the plasma and an iron core (Fig. 2). The main parameters are listed in Table I.

The design concept includes features fulfilling specific requirements such as ample radial and tangential access for observation ports, pumping ports, auxiliary heating beamlines, and the necessity of splitting TEXTOR into two parts in order to replace the inner wall (liner).

Good optical access to the plasma boundary and to the surface of the first wall led to the choice of a relatively small number of large-diameter toroidal field (TF) coils, a double-wall chamber, and an off axis position of TF coils.

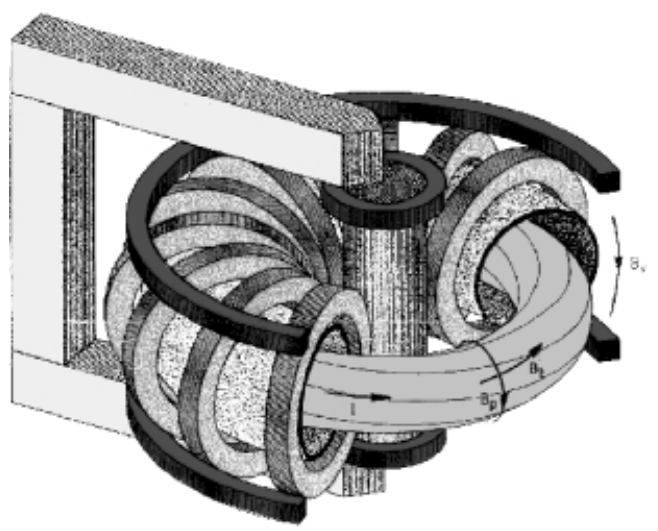

Fig. 2. Cutaway model showing the principal design of the TEXTOR tokamak.
TABLE I

Main Parameters of TEXTOR

\begin{tabular}{|l|c|}
\hline \multicolumn{1}{|c|}{ Plasma Boundary } & Limiter/DED \\
\hline Major plasma radius & $1.75 \mathrm{~m}$ \\
Average minor plasma radius & $0.47 \mathrm{~m}$ \\
Plasma shape & Circular \\
Plasma volume & $7 \mathrm{~m}^{3}$ \\
Number of TF coils & 16 \\
Magnetic field & $3.0 \mathrm{~T}$ \\
Plasma current & $0.8 \mathrm{MA}$ \\
Pulse length & $10 \mathrm{~s}$ \\
Installed heating power & $9 \mathrm{MW}$ \\
Auxiliary heating & NBI, ion cyclotron \\
& resonance heating, \\
& electron cyclotron \\
& resonance heating \\
\hline
\end{tabular}

\section{II.A. Mechanical Structure}

The mechanical structure ${ }^{2}$ mainly consists of a toroidal shell formed by the TF coils, the supports for the ohmic heating coils, the vertical field (VF) coils, and the vacuum vessel as well as a splittable base plate with its support. The transformer core consisting of a central leg and six yokes is mounted on a separate support (Fig. 3).

The toroidal shell is set up of $16 \mathrm{TF}$ coil steel casings. Together they form a vault near the machine axis keeping the iron core free of centripetal forces. The individual coil casings are prevented from lateral sliding by a groove-key system at the center. At the outer circumference they are additionally coupled by steel elements located above and below the equatorial plane. The configuration described results in a double-shell structure

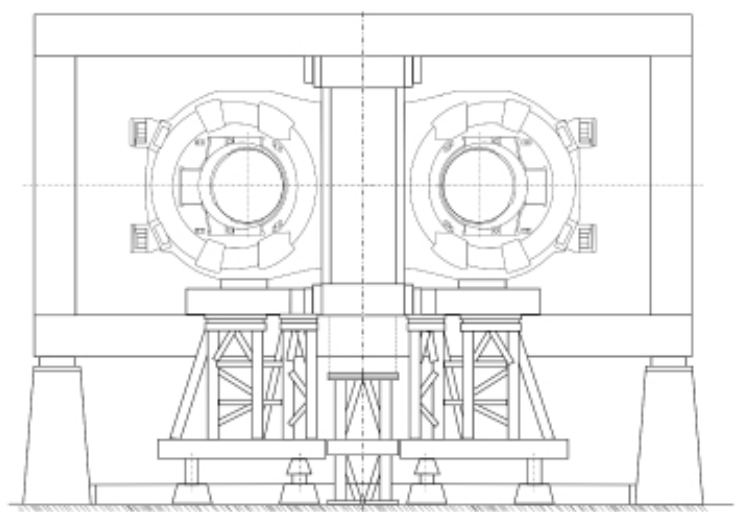

Fig. 3. Schematic drawing of TEXTOR (poloidal sectional view). The TEXTOR device and the iron core are mounted on separate support structures. 
capable of taking both the centripetal forces (up to 3500 $\mathrm{kN} /$ coil) and the tilting moments (up to $470 \mathrm{kNm}$ ) produced by the magnetic field.

Saddles attached to the TF coil casings support the VF coils also transmitting the forces acting on these coils to the shell structure. The vacuum vessel support mounted on the toroidal shell is equipped with sliding bearings, allowing for thermal expansion of the vessel in the toroidal direction. The vessel segments are equipped with a sliding joint on the top, allowing for thermal expansion on one hand and preventing them from vertical movement during disruptions on the other hand.

The whole arrangement is designed for being routinely split into two parts. Thus, the structure is positioned on a splittable base plate of $\sim 6 \mathrm{~m}$ in diameter carrying the complete weight of the experiment of $\sim 200 \mathrm{t}$. The base plate itself is mounted on a supporting framework-type structure fitted out with roller-bearing devices. Thus, access to the machine also from below is possible. The toroidal shell, the VF coils, and the vacuum vessel are also prepared for splitting. After removal of a single transformer yoke, about one-half of the machine can be rolled off for $3.5 \mathrm{~m}$ in order to be able to remove the liner.

All toroidal electrical loops set up by the structure are isolated by glass fiber impregnated with epoxy resin in order to avoid induced voltages at plasma start-up or disruptions.

\section{II.B. Coils and Electrical Systems}

\section{II.B.1. Coils}

Figure 4 gives an overview on the coil configuration consisting of TF coils, ohmic heating coils, the shaping coil, the VF coil, and position control coils. The DED coils being the main component of a special tool for manipulation of the plasma edge are described in Sec. V.

The TF magnet ${ }^{3}$ generating up to $3 \mathrm{~T}$ at $82 \mathrm{kA}$ at the plasma center with a $<1.5 \%$ ripple at the boundary consists of 16 coils connected in series with 20 turns each. The winding packages of water-cooled copper conductors are designed for an adiabatic temperature rise of $\sim 40 \mathrm{~K}$ during a plasma pulse followed by a cooldown phase. The single turns as well as the complete coils are insulated by epoxy resin impregnated glass fibers. The winding packs are embedded elastically in steel casings that take the electromagnetic forces. Sufficient clearance between coils and casings allows for appropriate thermal expansion.

The poloidal field $(\mathrm{PF})$ coils are water-cooled copper coils insulated with mica embedded in epoxy resin impregnated glass fibers. The upgraded ohmic heating coil with 294 turns in total is capable of producing $8.8 \mathrm{Vs}$ at $\pm 36 \mathrm{kA}$. This requires considerable saturation of the iron core up to $4.5 \mathrm{~T}$. The stray field in the plasma volume arising from the core in this case is compensated by properly fed shaping coils on top of the ohmic heating coils.

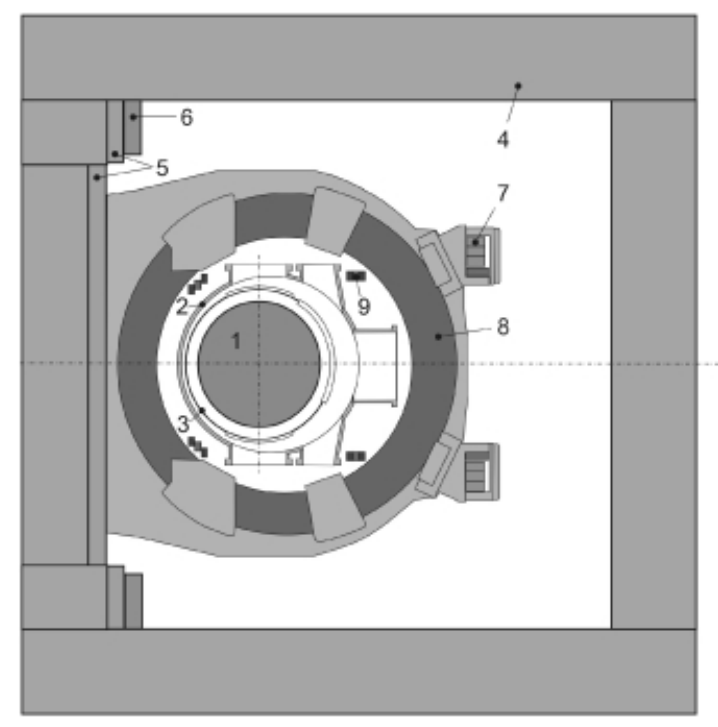

Fig. 4. Sectional view of TEXTOR: $1=$ plasma, $2=$ vacuum vessel, $3=$ liner, $4=$ transformer core, $5=$ ohmic heating coil, $6=$ shaping coil, $7=\mathrm{VF}$ coil, $8=\mathrm{TF}$ coil, and $9=$ position control coils. Symmetry referred to the horizontal center plane.

All three PF systems act more or less independently. The iron core flux is dominated by the ohmic heating coil because of its large number of turns, whereas their contribution to the vertical field is rather low. The shaping coils produce local effect only. Finally, the VF coils ${ }^{4}$ generate a rather homogeneous field that counteracts the plasma pressure.

Two sets of position control coils generate either pure vertical or horizontal fields. Since they consist of an equal number of turns both clockwise and counterclockwise around the iron core, they do not magnetize the core, thus allowing fast control of the plasma position.

The outer fast position control coils and the VF coils are prepared for splitting into two halves. ${ }^{4}$ The contacts are set up of silvered socket elements plugged with silvered pins. Reliable electrical contact is ensured by lamella contacts on the circumference of the pins. At the pin's ends, seals are inserted, keeping the contact area free of cooling water.

\section{II.B.2. Power Supplies}

Because of the concentration of power stations around the TEXTOR site, the required pulse power of $\sim 125 \mathrm{MW}$ is directly supplied from the $110-\mathrm{kV}$ line (Fig. 5) at $\sim 1$-km distance from the experiment. ${ }^{5,6}$ Thus, no energy storage system such as flywheel or capacitor bank is necessary. Two power transformers of 40 MVA each supply the $21-\mathrm{kV}$ feeder systems. Two harmonics filters are installed, both compensating partly the reactive power of the thyristor converters and filtering the typical harmonics 


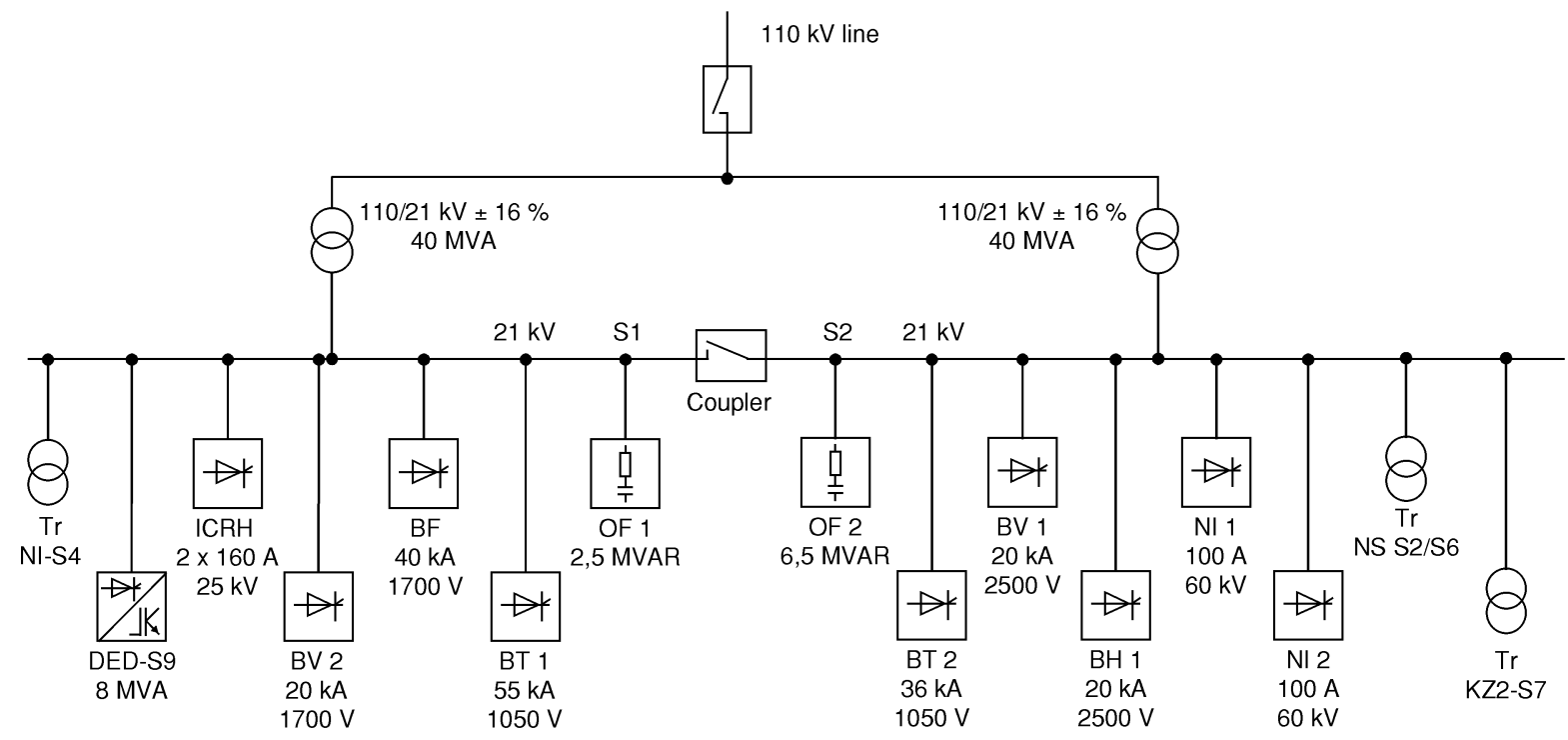

Fig. 5. The 21-kV feeder systems of TEXTOR. Two power transformers feeding a 21-kV busbar each. Rectifier transformers and auxiliary supply transformers (Tr) as well as harmonics filters (OF) fed by the busbars.

of 12-pulse rectifiers, which represent the major part of the power supplies. The total installed converter power amounts to $\sim 300$ MVA.

The design of the individual power supplies mainly has been determined by the requested power together with the necessary response time. Conventional 12-pulse thyristor converters with freewheeling diodes supply the TF coils, the ohmic heating coils, the VF coils, and the shaping coils. Detailed parameters are listed in Table II.
Since in the presence of a stray field in the plasma volume the voltage produced by the ohmic heating power supply is not sufficient for plasma start-up, a specially designed breaker circuit is connected in series (Fig. 6).

The start-up voltage is generated from a voltage drop on a resistor (RK) carrying the ohmic heating current. For this purpose the current is interrupted by a vacuum switch (SV) using a forced commutation circuit (SK, CK, LK, LS) and bypassed into the commutation resistor.

TABLE II

Main Parameters of TEXTOR Power Supplies

\begin{tabular}{|c|c|c|c|c|c|}
\hline Power Supply & Symbol & $\begin{array}{c}\text { No-Load } \\
\text { Voltage } \\
(\mathrm{kV})\end{array}$ & $\underset{(\mathrm{kA})}{\text { Current }}$ & $\begin{array}{l}\text { Pulse Power } \\
\text { (MVA) }\end{array}$ & Remark \\
\hline \multirow[t]{2}{*}{ Toroidal field } & BT-1 & 1 & 55 & 55 & \multirow[t]{6}{*}{ Line commutated thyristor converter } \\
\hline & BT-2 & 1 & 36 & 36 & \\
\hline Shaping field & $\mathrm{BF}$ & 1.7 & 40 & 68 & \\
\hline Vertical field & BV-2 & 1.7 & 20 & 34 & \\
\hline \multirow[t]{3}{*}{ Start-up and ohmic heating } & BV-1 & 2.5 & 20 & 50 & \\
\hline & BH-1 & 2.5 & 20 & 50 & \\
\hline & MSK & 25 & 36 & $900(16,7 \mathrm{MJ})$ & Current commutation with two vacuum \\
\hline \multirow[t]{4}{*}{ Fast position control } & $\mathrm{KR}$ & 0.62 & 0.75 & 0.5 & Force commutated converter with direct \\
\hline & $\mathrm{KZ}$ & 0.72 & 2.7 & 2.0 & $\begin{array}{l}\text { voltage intermediate circuit, } 2-\mathrm{kHz} \text { clocking } \\
\text { Force commutated converter with direct }\end{array}$ \\
\hline & & & & & voltage intermediate circuit, $2-\mathrm{kHz}$ clocking \\
\hline & $2 \times \mathrm{KZ}-2$ & 0.6 & 5.4 & $2 \times 3.25$ & $\begin{array}{l}\text { Transistor converter with direct voltage } \\
\text { intermediate circuit } 40-\mathrm{kHz} \text { clocking }\end{array}$ \\
\hline Neutral beam injector & $2 \times \mathrm{NI}-\mathrm{ACC}$ & 60 & 0.1 & $2 \times 6$ & Pulse step modulator with, stages, $0.9 \mathrm{kV}$ each \\
\hline DED & $9 \times \mathrm{DED}$ & 0.6 & 1.5 & $9 \times 0.9$ & IGBT converter, maximum $10 \mathrm{kHz}$ \\
\hline
\end{tabular}




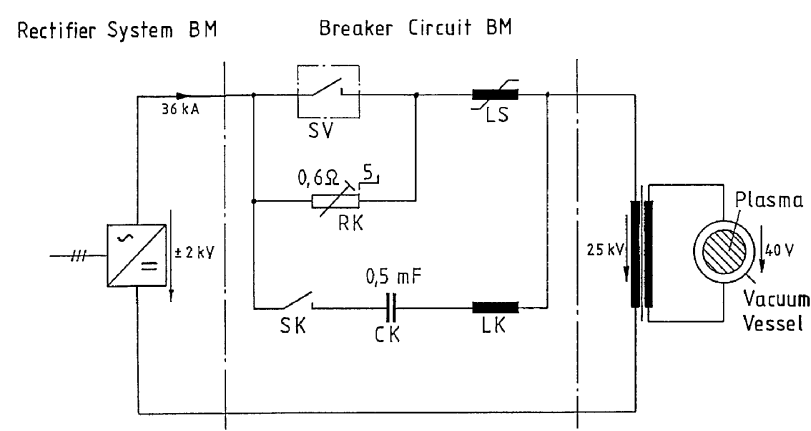

Fig. 6. Breaker circuit in the ohmic heating coil power supply generating the necessary voltage for plasma start-up by commutating the magnetizing current via the commutation circuit (SK, CK, LK, LS) into the resistor (RK).

The latter is adjustable for the choice of an appropriate voltage of $\sim 12 \mathrm{~V}$. After plasma start-up the commutation resistor is short-circuited again, allowing normal operation of the ohmic heating system.

Fast position control of the TEXTOR plasma requires response times faster than those of the main commutated converters. Force commutated thyristor converters had been chosen at the beginning. Meanwhile, the horizontal position control has been upgraded with a transistor converter ${ }^{7}$ in order to cope with the requirements of enhanced plasma performance. For details, see Table II.

All PF systems are protected from dangerous voltages arising from the stored energy in the magnetic field by a multilevel overvoltage protection system. ${ }^{8}$ Directly at the coil terminals, varistor units limit the transient overvoltages. Crowbar thyristors connected in parallel to the power supplies protect them by spontaneous ignition in case of overvoltages. In case a single crowbar thyristor in one PF system responds, all remaining units are triggered too. At the same time, except for the position control systems being only weakly magnetically coupled to the other systems, vacuum crowbar switches are closed, relieving the thyristors within $40 \mathrm{~ms}$. Finally, diodes block reverse voltage induced during plasma start-up.

\section{II.B.3. Sequence of Currents}

Figure 7 shows current traces of a typical TEXTOR discharge. The toroidal field is switched on first and switched off last because of the low gradient. This guarantees a constant field during the plasma phase.

Subsequently, the iron core is magnetically loaded by ramping up the ohmic heating current. This is followed by plasma start-up initiated from a voltage pulse generated by the commutation circuit. The plasma current is then ramped up and maintained at a constant level by ramping down the magnetizing current to the most negative value.

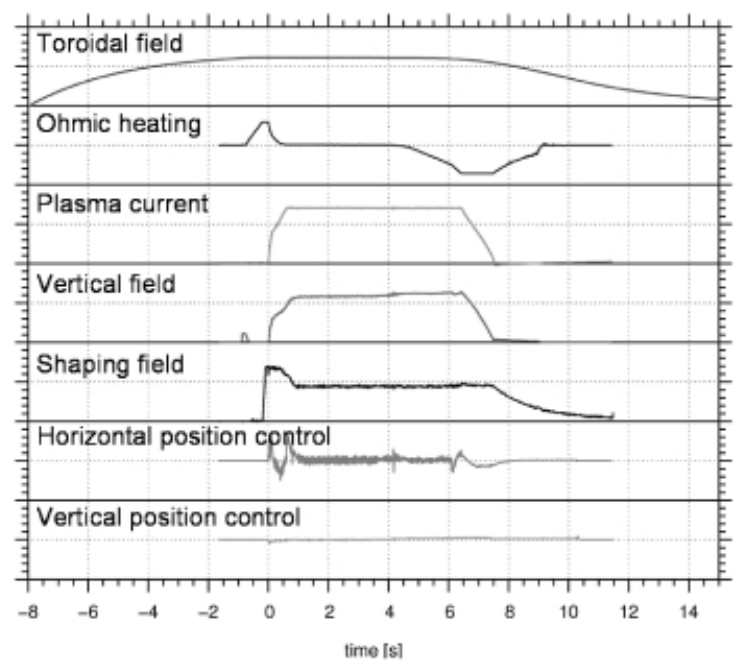

Fig. 7. Current traces (arbitrary units) of a typical TEXTOR discharge.

The vertical field is mainly proportional to the plasma current in case of constant plasma energy contents. The shaping field is used for compensation of the stray fields, both facilitating the start-up phase and maintaining a circular plasma cross section. As long as the plasma properties are constant, the average values of the position control currents are zero. A discharge is terminated by preprogrammed rampdown of the plasma current using the magnetizing current or at the latest if the magnetic flux has reached the maximum negative value.

\section{II.B.4. Grounding System}

Grounding of the PF coils has to preserve stable electrical potentials at the terminals. Additionally, detection of ground faults is necessary. By connecting all center taps of the windings via resistors to the ground, the maximum voltage from the terminal to the ground is reduced to half of the coil voltage. Monitoring the currents flowing in the grounding resistors allows for ground fault detection followed by fast deenergizing of the coils.

\section{II.C. Vacuum Vessel and First Wall}

\section{II.C.1. Vacuum Vessel and Liner}

The vacuum vessel ${ }^{9}$ of TEXTOR is welded of four large rigid sections, four small rigid sections connected, and eight bellows. The material of the rigid sections is stainless steel 1.4311 with a thickness of $25 \mathrm{~mm}$, whereas the 0.5 -mm-thick bellows are made of stainless steel 1.4848. Between rigid segments and bellows, lip welds have been chosen, allowing for replacement of vessel elements. The geometry of the bellows was adjusted to a toroidal resistance of the vessel of $4 \mathrm{~m} \Omega$. 
Large portholes are available for instance for rf antennas, NBI, and pumping. Additionally, more than 300 radial and tangential portholes on top and bottom as well as at the equator plane give excellent access to the plasma for diagnostics.

Heating of the vacuum vessel for baking purposes is done by pumping heat transfer oil through pipes welded on the vessel surface.

A separate toroidal wall - the liner-is mounted with an average distance of $70 \mathrm{~mm}$ inside the vacuum vessel. It represents the first wall next to the plasma, being the main object of plasma-wall interaction studies. The liner is 64 tubular segments welded together. The thickness of the material (INCONEL) is $1 \mathrm{~mm}$. Reinforcements at portholes give sufficient mechanical stiffness. For thermal wall conditioning direct current $(\mathrm{dc})$ is fed into the liner from opposite toroidal positions. Baking is performed at $300^{\circ} \mathrm{C}$ routinely while the maximum temperature is $500^{\circ} \mathrm{C}$.

\section{II.C.2. Limiters}

The inner wall of TEXTOR is equipped with several limiters (Fig. 8) mostly covered by carbon protecting the liner from the plasma energy, shaping the plasma, and partly being designed for material testing. On the highfield side of the vessel, the fully toroidal bumper limiter protects about one-third of the poloidal circumference

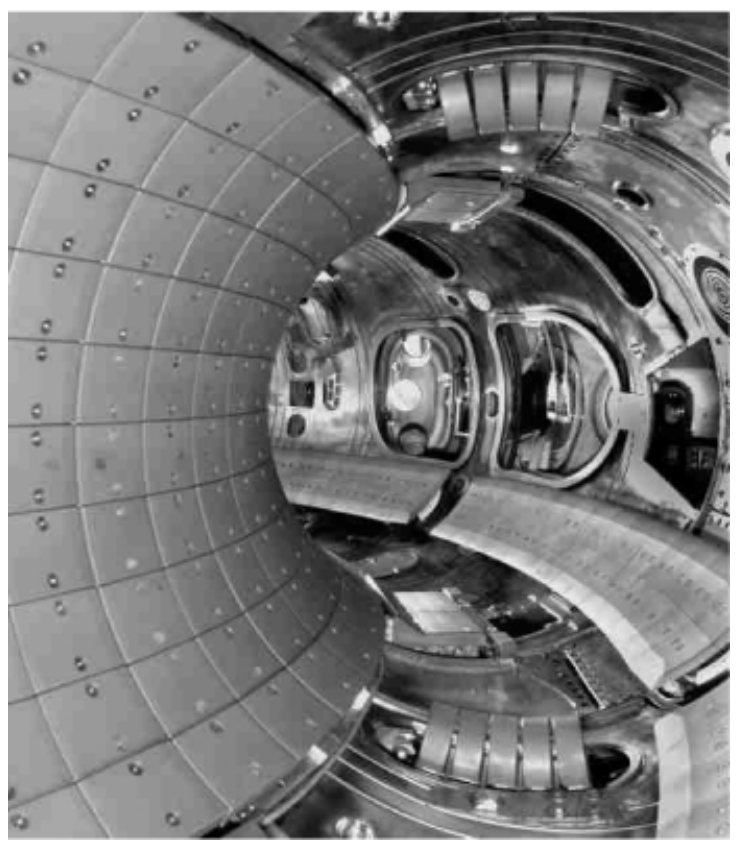

Fig. 8. Photograph of the TEXTOR limiters protecting the liner from the plasma energy, shaping the plasma, and partly being designed for material testing. The bumper limiter (left), the main limiters (top and bottom), and the ALT-II (right). from the energy of the plasma deposited in case of a disruption. This allows for plasma position close to the high-field side. The presence of the DED described in Sec. V enhances its function to a divertor target. Main limiters at a certain toroidal position mounted poloidally on top and bottom as well as on the low-field side can remotely be moved into the plasma for shaping and material testing purposes. A number of protecting limiters are installed on parts close to the plasma such as the rf heating antennas.

Finally, the Advanced Limiter Test II (ALT-II) (Refs. 10 and 11) of TEXTOR is a full toroidal belt limiter for investigation of the effects on particle confinement and recycling control mounted 45 deg below the equator plane on the low-field side. It is designed to operate with up to $8 \mathrm{MW}$ plasma heating for $10 \mathrm{~s}$.

The limiter consists of eight individual blades forming a full toroidal belt. Each of 28 graphite tiles is mounted onto a 6 -mm-thick INCONEL ${ }^{\circledR} 625$ base plate. The base plate curvature is fitted poloidally and toroidally to the torus and provides structural support in order to withstand disruption forces. The limiter tiles are thin $(17 \mathrm{~mm})$ in order to optimize particle collection and profiled in order to distribute the incident heat flux. On the back of the base plates, properly shaped scoops guide the particles into the pump duct (Fig. 9).

\section{II.C.3.Discharge Cleaning System}

TEXTOR is outfitted with a combined rf glow discharge system. It is operated at a pressure of $\sim 10^{-3}$ mbars. The apparatus consists of four antennas. The output of an rf amplifier and a positive dc voltage are applied simultaneously to these structures, making them anodes in the discharge. The wall is grounded and thus cathode. The cleaning method is completed by a residual gas analysis.

\section{CONTROL SYSTEM}

The topology (Fig. 10) of the TEXTOR control system $^{6,12}$ is defined by several links between central

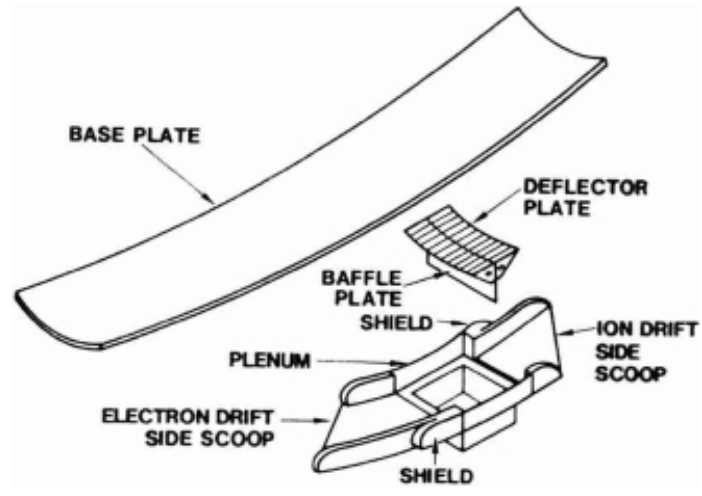

Fig. 9. Schematic view of the ALT-II components. 


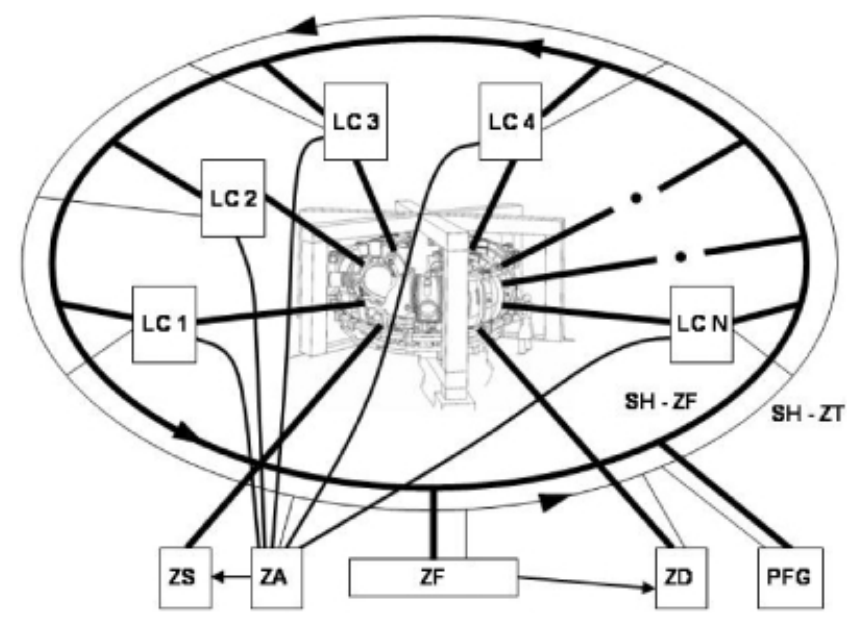

Fig. 10. Topology of the control system of TEXTOR. Two fiber-optic rings ( $\mathrm{SH}$ ) connect local control units (LC) with central control units $(\mathrm{Z})$

control units and local control units. All subsystems such as electrical systems, heating and cooling systems, the vacuum system, the gas inlet system, and cleaning systems are equipped with programmable logic controllers (LC) including switch panels and displays giving the opportunity for local operation. The local control systems are linked via two fiber-optic rings. One $\mathrm{SH}-$ $\mathrm{ZF})$ is connected to the central control unit $(\mathrm{ZF})$. The other (SH-ZT) is controlled by the central timing system (ZT) with 1- $\mu$ s resolution. Direct links exist from local control units to the central sequence control (ZA), which coordinates switch-on and switch-off sequences as well as intersubsystem interlocks. A completely independent control system (ZS) in double configuration that is partly hard wired takes care of safety. The central control unit $(\mathrm{ZF})$ is configured for remote control of the local units, the timing system, the sequence control, and the safety system. The data acquisition system (ZD) is linked in a similar way to the control system. TEXTOR data are stored in a database having a Web interface that allows evaluation independently of the computer platform.

Reference values of the plasma parameters such as the plasma current, the plasma position, the plasma density, and others are defined by a programmable function generator. When triggered by the central timing, it delivers analog values to the feedback controllers of the corresponding subsystems. All feedback controllers are implemented on DSP boards, which are partly linked among each other. This gives the opportunity to anticipate the actuator's set value, roughly leaving only a small deviation from the reference value to be adjusted by the feedback control. This concept results in stable and precise control of the plasma current and plasma position independent of the magnetizing state of the iron core.

\section{NEUTRAL BEAM INJECTORS}

It is commonly known that appropriate fusion research with tokamaks requires auxiliary heating of the plasma since ohmic heating is naturally limited. For this reason TEXTOR has very early been upgraded by installing two neutral particle injectors. ${ }^{6}$ Radio frequency heating and microwave heating, which are available as well, are described in Refs. 13 and 14, respectively. The neutral beamlines are arranged tangentially to the plasma in order to obtain a long absorption path. The units inject parallel to the ion current (coinjection) and in opposite direction to the ion current (counterinjection), respectively.

Each injector is composed of a vacuum tank with an ion source and an acceleration system (Fig. 11). The ion beam is neutralized by $50 \%$ in a gas cell (neutralizer). The remaining ions are deflected by a divertor magnet and directed toward a beam dump. The gas leaving the neutralizer is pumped with cryopumps. In order to keep the amount of cold neutral gas leaking into the vacuum vessel of TEXTOR as small as possible and to avoid reionization of the beam, the volume between the divertor magnet and the TEXTOR vessel is pumped differentially. Table III lists the main parameters.

High-voltage power supplies of $2 \mathrm{MW}$ each, adjustable between 20 and $60 \mathrm{kV}$, deliver the energy for particle acceleration.

\section{DYNAMIC ERGODIC DIVERTOR}

\section{V.A. General Layout}

Recently, TEXTOR has been upgraded by installing the DED (Ref. 15). The purpose of the DED is to influence transport parameters in the plasma edge and to study the resulting effects on heat exhaust, edge cooling, impurity screening, plasma confinement, and stability. The DED creates alternatively static or rotating multipolar

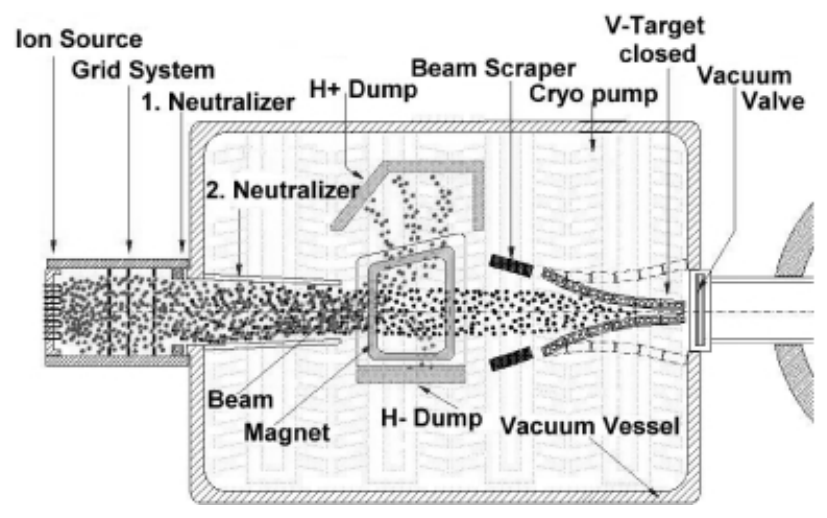

Fig. 11. Schematic view of a neutral beam injector for TEXTOR. 
TABLE III

Main Parameters of the Neutral Beam Injectors for TEXTOR

\begin{tabular}{|ll|}
\hline Particle energy & $20 \ldots 60 \mathrm{keV}$ \\
Equivalent neutral current & $100 \mathrm{~A}$ \\
Time on/off & $15 / 300 \mathrm{~s}$ \\
Beam cross section & $400 \times 320 \mathrm{~mm}$ \\
Beam divergence & $<1 \mathrm{deg}$ \\
Working gas & $\mathrm{H}_{2}, \mathrm{D}_{2},{ }^{3} \mathrm{He},{ }^{4} \mathrm{He}$ \\
\hline
\end{tabular}

helical magnetic perturbation fields of different mode patterns. The coil arrangement is shown in Fig. 12.

A set of 16 helical coils has been installed on the inboard high-field side of the vacuum vessel covering $\sim 30 \%$ of the inboard vessel surface. The coils are aligned parallel to the magnetic field lines at the nearby $q=3$ surface $\left(r \approx 43 \mathrm{~cm} ; \beta_{p o l}=1\right)$; they follow the torus on the high-field side for one complete turn in the toroidal direction. Two additional coils are installed to compensate for the stray field, generated by the nonideal feeding. These compensation coils are located immediately above and below the set of ergodization coils, running parallel to them.

To accommodate the coils and their support segments, the corresponding area of the TEXTOR liner has been removed. All 18 coils (16 ergodization coils plus 2 compensation coils) are mounted in an array of poloidal belt segments. The coils are covered by graphite tiles that act both as divertor target plates and bumper limiter (Fig. 13).

The peak current in the individual coils is $15 \mathrm{kA}$ for pulse durations up to $10 \mathrm{~s}$. A set of nine identical frequency convertor units ${ }^{16}$ feeding two coils connected in series each is used at a total power of 8.1 MVA.

The main parameters of the system are listed in Table IV.

All the terminals of the coils are accessible from the outside of the vessel, allowing coil connections to be changed for the different modes without breaking the vacuum.

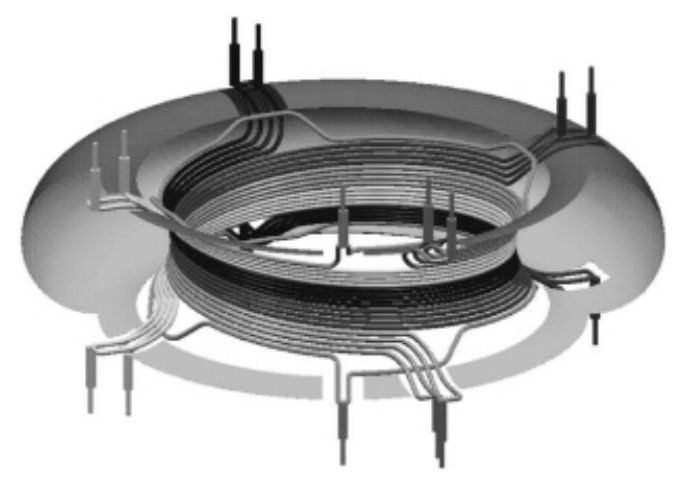

Fig. 12. The DED coils inside the TEXTOR vacuum vessel.

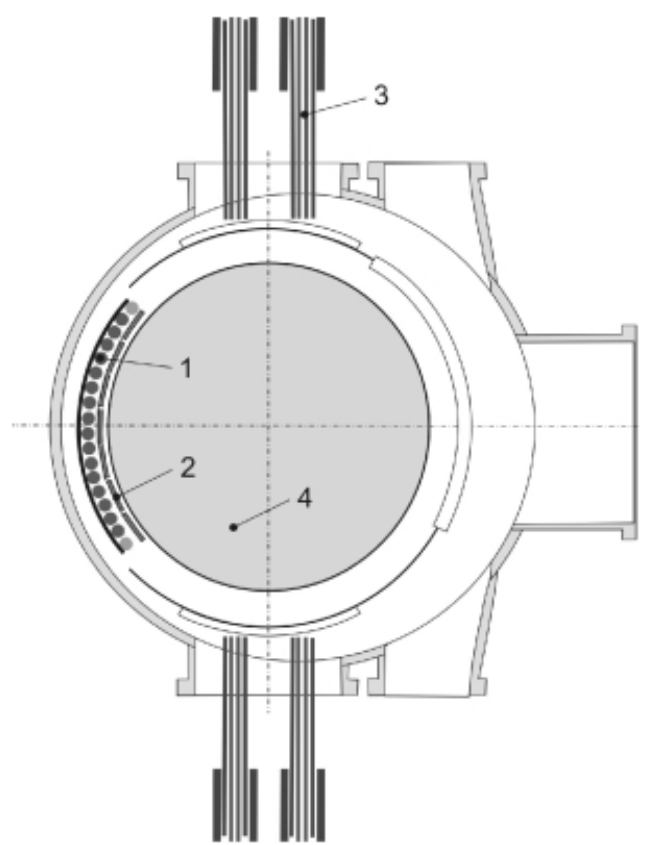

Fig. 13. Poloidal cross section showing (1) the DED coils and (2) the divertor target plates inside the vacuum vessel close to the (4) plasma, as well as (3) the coaxial feedthroughs.

\section{V.B. Coil Design}

A novel coil (Fig. 14) has been developed that fulfills the various mechanical, electrical, high-frequency, thermal, and vacuum requirements.

TABLE IV

Main Characteristics and Parameters of the DED for TEXTOR

\begin{tabular}{ll}
\hline Number of coils & $16(\mathrm{DED})+2$ (compensation) \\
Turns per coil & 1 \\
Conductor & $6 \times 7 \times 7$ twisted copper wires \\
Wire diameter & $0.95 \mathrm{~mm}$ \\
Current density & $72 \mathrm{~A} / \mathrm{mm}^{2}$ \\
Wire insulation & Polyimide, $0.05 \mathrm{~mm}$ \\
Cooling & Helium gas $/$ water \\
Maximum coil & \\
$\quad$ & $250^{\circ} \mathrm{C}$ \\
temperature & $\sim 7 \mu \mathrm{H}$ \\
Coil inductance & $\sim 2 \mathrm{~m} \Omega(\mathrm{dc} \ldots 1 \mathrm{kHz})$ \\
Coil resistance & $14 \mathrm{~m} \Omega(10 \mathrm{kHz})$ \\
& $10 \mathrm{~s} / 360 \mathrm{~s}$ \\
Time on/off & $15 \mathrm{kA}(\mathrm{dc} \ldots 1 \mathrm{kHz})$ \\
Coil current (peak value) & $10.6 \mathrm{kA}(1 \mathrm{kHz} \ldots 5 \mathrm{kHz})$ \\
& $7.5 \mathrm{kA}(5 \mathrm{kHz} \ldots 10 \mathrm{kHz})$ \\
& $\sim 2.5 \mathrm{kV}$ \\
Maximum coil voltage & $9-\times 0.9-\mathrm{MW} \mathrm{IGBT} \mathrm{converter}$ \\
Power supply &
\end{tabular}




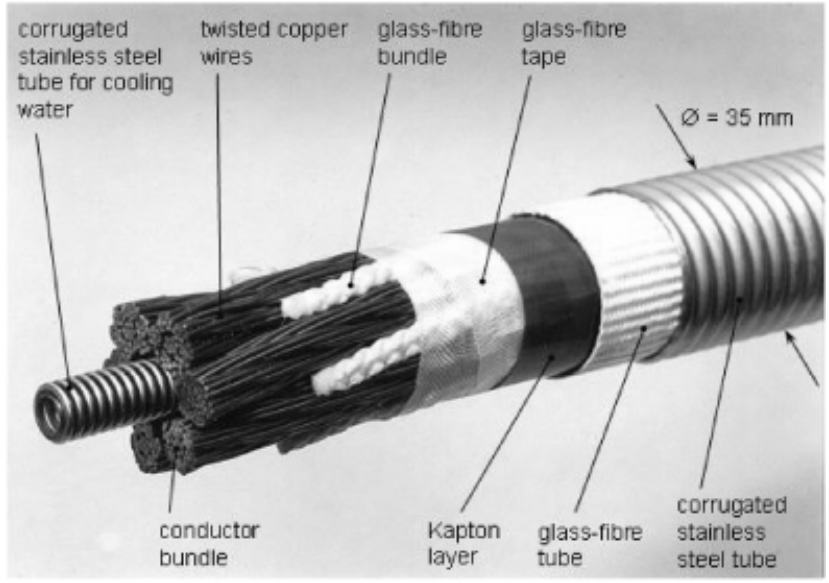

Fig. 14. DED conductor with $6 \times 7 \times 7$ twisted and insulated copper wires.

For this purpose, and in order to cope with eddy currents and skin effects, to fulfill the cooling requirements, to limit the adiabatic temperature rise (pulse duration $\leq 10 \mathrm{~s}$ ), and to make optimal use of the limited space, a special conductor (cable) has also been developed. It consists of 294 insulated and twisted copper wires. All bundles of the conductor are twisted in order to enforce a homogeneous current distribution among the wires and to reduce the eddy current losses.

All bundles and subbundles are unidirectionally twisted and act like a spring that tolerates the thermal expansion of the conductor. The wires are insulated by polyimide (thickness: $0.05 \mathrm{~mm}$; maximum working temperature: $250^{\circ} \mathrm{C}$ ), which withstands voltages of up to $10 \mathrm{kV}$. The wires are protected against mechanical damage by glass-fiber bundles, glass-fiber taping, and a glassfiber tube: The whole is enclosed by a corrugated stainless steel tube of $0.2-\mathrm{mm}$ wall thickness. Thus, thermal expansions of the conductor and vessel as well as vibrations of the vessel during disruptions can be compensated.

The magnetic forces acting on the individual coil amount to $3.5 \mathrm{kN} / \mathrm{m}$ at the divertor and $45 \mathrm{kN} / \mathrm{m}$ at the internal feeders (where the coil current flows perpendicular to the toroidal magnetic field). The forces are transmitted from the conductor to the support structure by the glass-fiber filling material described above.

Cooling of the coils is realized by a combination of water and helium. The remaining voids inside and around the conductor are filled with slowly streaming helium gas, which ensures an efficient heat transfer from the conductor to the water-cooled central tube. The cooling water inside the central tube transports the energy effectively along the coil to the outside cooling circuit. Thus, the duration of the cooling-down phase can be kept below $10 \mathrm{~min}$ for full-performance operation.

\section{V.C. In-Vessel Components}

In order to accommodate the coils without reducing the present minor radius of the plasma, the coils are recessed into the liner. This required a cutout of parts of the liner. The original vertical stiffness of the liner is guaranteed by new edge reinforcements and supports.

The ergodization coils are positioned by clamps and C-shaped belts at the inboard side of the vessel (Fig. 15). The coils are protected by graphite tiles that act as divertor target plates or as a bumper limiter. They are mounted on a poloidal support structure, which is connected to the vessel above and below the ergodization coils. This support structure, together with the vessel, acts as a Faraday cage and thus also protects the coils against halo currents in case of disruptions. Additional ceramic tiles act as thermal insulation between the divertor tiles and coils, also enabling baking of the divertor tiles and the liner at temperatures $>300^{\circ} \mathrm{C}$.

\section{V.D. Feedthroughs}

Eighteen feedthroughs ${ }^{17}$ (Fig. 16) connect the coil currents and the cooling media from inside the vacuum vessel to the outside atmosphere. Each feedthrough consists of two conductors arranged coaxially.

For the standard mode $(m=12 ; n=4)$, the currents in the two conductors have opposite directions. This considerably reduces eddy current losses in the conductor as well as the resulting magnetic forces.

\section{V.E. Power Supply System}

The required four-phase current is generated by two sets of power units with a 90-deg phase shift. The

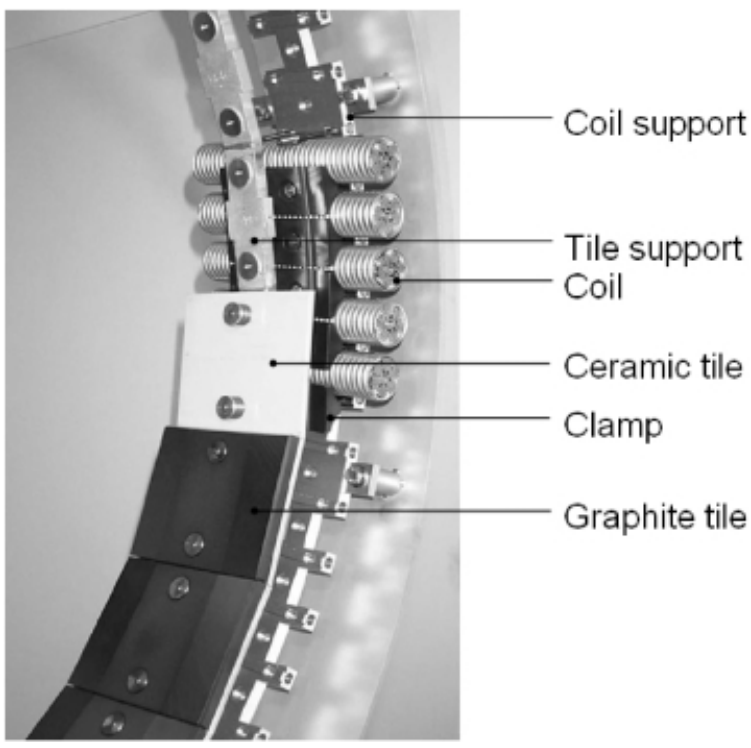

Fig. 15. Mockup of a DED segment showing the coils cut and the divertor target plates with thermal insulation. 


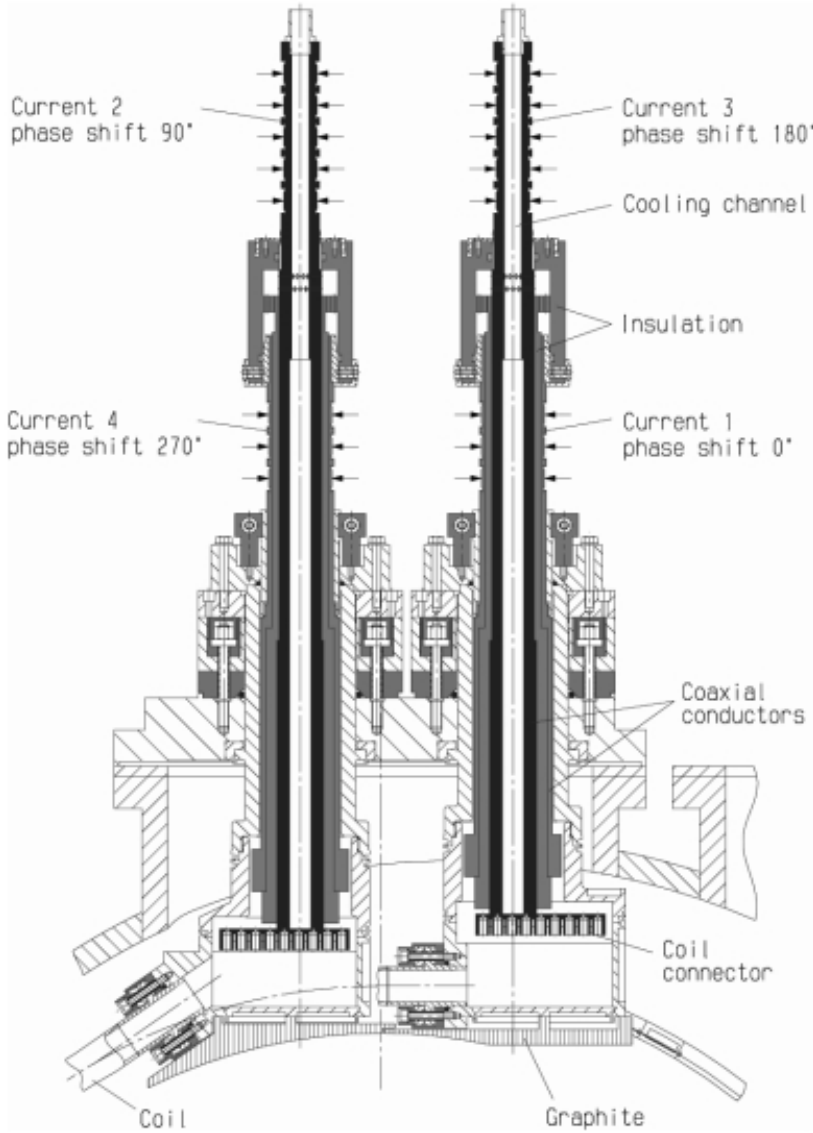

Fig. 16. Two coaxial feedthroughs connecting four-phase alternating current and the cooling media from the vacuum vessel (bottom) to the outside (top).

arrangement of the components is shown in Fig. 17. The endings of two coils are connected and grounded by a $10-\Omega$ resistor that reduces the maximum voltage to ground to half the coil voltage of $2.5 \mathrm{kV}$. In all operation modes the coils and the power units that run at the same phase shift are connected in series. The two compensation coils are also connected in series and are fed by one 45-deg power unit. In the frequency range from 1 to $10 \mathrm{kHz}$, a special transformer decouples the 0 -deg system and the 90-deg system in order to suppress mutual power transfer.

Nine identical frequency converter units (Fig. 18) are required to energize the coils. The output voltage of each unit is $600 \mathrm{~V}$, and the peak current is $1.5 \mathrm{kA}$. The driving voltage of $600 \mathrm{~V}$ was chosen to minimize the cost of the power supply system. The nine converter units are supplied from the existing $21-\mathrm{kV}$ station of TEXTOR by one power transformer of $21 \mathrm{kV} / 500 \mathrm{~V}$.

For reactive power compensation, capacitors are connected in series to each double coil (load unit). Matching transformers adapt the coil parameters $(60 \mathrm{~V} ; 15 \mathrm{kA})$ to the converter parameters $(600 \mathrm{~V}, 1.5 \mathrm{kA})$. To allow for $\mathrm{dc}$

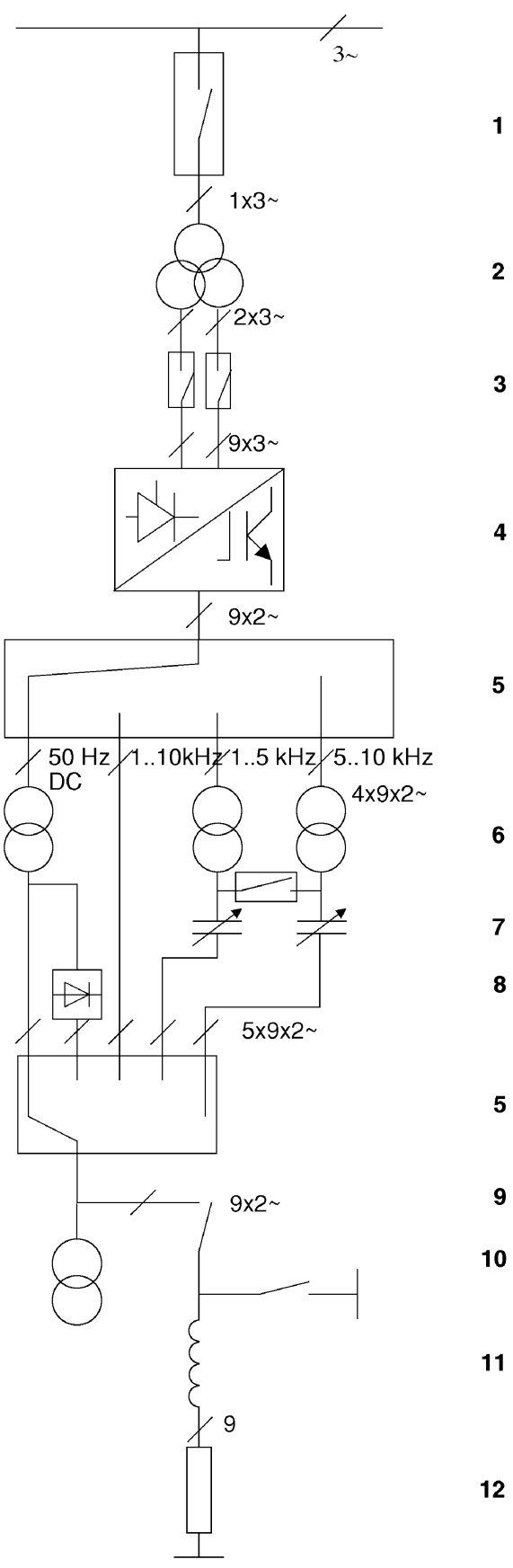

Fig. 17. Power supply circuit for the divertor coils. Power supply components: $1=21-\mathrm{kV}$ circuit breaker; $2=$ rectifier transformer; $3=$ circuit breakers; $4=$ frequency converter; $5=$ operating mode selector; $6=$ matching transformers; 7 = capacitor banks; $8=$ diode rectifier; $9=$ disconnector, earthing; $10=$ decoupling transformer; $11=$ DED coil; and $12=$ grounding resistance.

operation, diode rectifiers are installed between the $50-\mathrm{Hz}$ matching transformer and the ergodization coils. The required synchronization of all power units is enforced by the central control unit. 


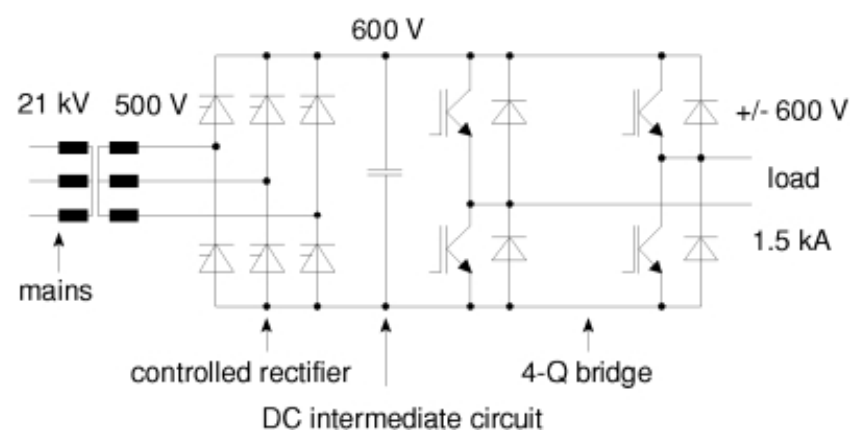

Fig. 18. Frequency converter unit with IGBTs and controlled dc intermediate circuit.

\section{CONCLUSION}

The number of special features and the flexibility of TEXTOR provide excellent opportunities for important contributions to fusion research. Especially, the DED is a unique flexible tool that extends the knowledge of particle and energy transport.

\section{REFERENCES}

1. H. CONRADS, “TEXTOR," Proc. 10th Symp. Fusion Technology, Padua, Italy, September 4-8, 1978 (1978).

2. W. KOHLHAAS et al., "The Mechanical Structure of TEXTOR," Proc. 10th Symp. Fusion Technology, Padua, Italy, September 4-8, 1978 (1978).

3. B. GIESEN et al., "The Toroidal Field Magnet of TEXTOR," Proc. 10th Symp. Fusion Technology, Padua, Italy, September 4-8, 1978 (1978)
4. M. LOCHTER, "Design of a Splittable Coil for the Poloidal Field System of TEXTOR," Proc. 10th Symp. Fusion Technology, Padua, Italy, September 4-8, 1978 (1978).

5. "TEXTOR Association KFA-EURATOM Technical Data I," Internal Report, Kernforschungsanlage Jülich (1980).

6. "Survey on the Fusion Research in the EURATOM-KFA Association," Internal Report, Kernforschungsanlage Jülich (1983).

7. B. GIESEN et al., "The New 20 kHz Switch-Mode Power Supply in Transistor Technology for the TEXTOR Plasma Position Control," presented at 16th Symp. Fusion Technology, London, Great Britain, 1990.

8. B. GIESEN, "Over Voltage Protection System of the New TEXTOR Poloidal Field System," Proc. 17th Symp. Fusion Technology, Rome, Italy, September 14-18, 1992 (1992).

9. D. A. BUTZEK, "Vacuum Vessel and Pumping System of TEXTOR," Proc 10th Symp. Fusion Technology, Padua, Italy, September 4-8, 1978 (1978).

10. W. KOHLHAAS et al., Fusion Eng. and Des., 13, 3, 261 (1990).

11. G. W. BROWN, "Engineering Design of the ALT-II Limiter for TEXTOR,” Fusion Technol., 8, 1729 (1985).

12. M. HOPMANN, "The Design of a Computerized Control System for TEXTOR," Proc. 10th Symp. Fusion Technology, Padua, Italy, September 4-8, 1978 (1978).

13. R. KOCH et al., "Ion Cyclotron Resonance Heating on TEXTOR," Fusion Sci. Technol., 47, 97 (2005).

14. E. WESTERHOF et al., "Electron Cyclotron Resonance Heating on TEXTOR," Fusion Sci. Technol., 47, 108 (2005).

15. B. GIESEN et al., "Technical Lay Out of the DED," Fusion Eng. Des., 37, 341 (1997).

16. O. NEUBAUER and S. NOWAK, "The Power Supply System of the Dynamic Ergodic Divertor at TEXTOR-94," Fusion Eng. Des., 58-59, 53 (2001).

17. M. POIER et al., "Feedthrough for the Actively Cooled Dynamic Ergodic Divertor Coils at TEXTOR-94," presented at Institute of Electrical and Electronics Engineers/Nuclear and Plasma Sciences Society 17th Symp. Fusion Engineering, San Diego, California, 1997. 